DOI 10.5216/ia.v46i3.68472

\title{
A CONSTITUIÇÃO DE PEDAGOGIAS NEGRAS NA INTERNET: UM ESTUDO DAS NARRATIVAS PRODUZIDAS E DISSEMINADAS POR YOUTUBERS NEGRAS
}

\author{
Evelyn Santos Pereira \\ Prefeitura Municipal de Canoas (PMC), Canoas, Rio Grande do Sul, Brasil \\ MARIA ANGÉlICA ZUBARAN \\ Universidade Luterana do Brasil (ULBRA), Canoas, Rio Grande do Sul, Brasil
}

\begin{abstract}
REsUMo: O presente estudo aborda as narrativas e pedagogias culturais produzidas e disseminadas por youtubers negras no ambiente virtual. $O$ objetivo central do artigo é analisar como são construídas e narradas as pedagogias negras nos espaços digitais e dimensionar seu impacto na construção de identidades femininas negras. A pesquisa está situada no campo dos Estudos Culturais em Educação e a metodologia utilizada é a análise cultural, com inspiração na etnografia virtual. Entre os principais resultados da pesquisa, destaca-se que as narrativas de si, produzidas pelas influenciadoras digitais negras, configuram-se como parte dos novos ativismos contemporâneos, como novas formas de resistência e de autodefinição de identidades femininas negras alternativas, que acionam pedagogias culturais de contestação e de empoderamento de jovens mulheres negras.
\end{abstract}

Palavras-chave: Youtubers Negras. Narrativas Digitais. Pedagogias Negras.

\section{INTRODUÇÃO}

Resistir e superar a invisibilidade e o silenciamento de suas identidades tem sido o desafio enfrentado cotidianamente pelas mulheres negras que, de formas distintas, participaram da construção deste país. De Dandara às militantes e intelectuais negras contemporâneas, as mulheres negras sempre fizeram parte dos movimentos de enfrentamento ao racismo e ao sexismo, ainda que esses protagonismos tenham sido apagados da história oficial. Conhecer e visibilizar a trajetória dessas mulheres, que não só sobreviveram, mas que contribuíram para a manutenção de suas tradições culturais e que operaram pequenas e grandes transformações nos contextos nos quais estavam inseridas, nos mostra que a história precisa ser reescrita baseada em diferentes vozes.

Sabemos que a atuação dos Movimentos Feministas Negros possui uma ampla trajetória. Portanto, é preciso reconhecer a visibilidade e as conquistas que grupos de mulheres negras estão alcançando nos últimos anos como fruto de uma longa caminhada. Assim, de acordo com as mulheres ligadas ao movimento negro, particularmente, Jurema Werneck (2010): esses passos "vêm de longe". Dito isso, chama atenção o destaque que as pautas dos coletivos negros femininos estão adquirindo nas dinâmicas culturais da contemporaneidade, nas quais as mídias digitais ocupam um 
lugar central. Observamos um número crescente de mulheres negras que, na linguagem da rede, são chamadas de influenciadoras digitais, usando a internet como um megafone para ecoar vozes que, por muito tempo, foram silenciadas. Através das narrativas que veiculam em suas plataformas, atuam no sentido de ampliar e fortalecer as epistemologias negras e contribuem com as políticas do cotidiano que atravessam a vida de seus pares.

A partir da possibilidade de falarem por si mesmas, característica singular do ecossistema comunicativo da era digital e reivindicação histórica de intelectuais negras, algumas influenciadoras digitais estão fazendo circular, na internet, narrativas que contribuem para a desconstrução de discursos e estereótipos historicamente ligados aos corpos e identidades femininas negras. Essas influenciadoras narram experiências pessoais assentadas em diferentes posições de sujeito - acadêmicas, artistas, mães, modelos, empreendedoras etc. -, com isso, tencionam e subvertem marcações raciais arbitrárias que operaram por muito tempo como verdades na sociedade brasileira. Elas compartilham memórias individuais e coletivas, manifestando suas complexidades e singularidades, evidenciando a pluralidade que constitui as identidades negras femininas, (re)significando processos de construção e afirmação identitários.

Tais narrativas, segundo a perspectiva adotada neste estudo, operam no ambiente digital como pedagogias culturais. Este conceito é estabelecido por meio da articulação entre o campo da Educação e dos Estudos Culturais. Desse modo, entendemos por pedagogia cultural os múltiplos processos educativos que ocorrem na cultura, em diferentes locais e movidos por interesses de diversas ordens. São processos pedagógicos que ultrapassam as fronteiras das instituições escolares, interpelando os sujeitos a assumirem determinados discursos e a consumirem certos bens e serviços (WORTMANN, 2010). Nessa direção, a pedagogia envolve "um conjunto de saberes e práticas que cada indivíduo é incitado a fazer operar sobre si para tornar-se sujeitos de determinados discursos" (CAMOZZATO, 2012, p. 36).

\section{CONSTRUINDO PEDAGOGIAS NEGRAS NO AMBIENTE DIGITAL}

Ao longo dos processos de colonização e pós-colonização, os sujeitos negros foram narrados e representados de forma pejorativa e estigmatizada a partir do olhar do homem branco colonizador, ainda que esses discursos e representações tenham sido tensionados na teoria e na prática pelas intelectuais feministas negras.

Entre os pesquisadores dos estudos decoloniais, frisamos as contribuições da argentina María Lugones (2019), cujas pesquisas centram-se em analisar as formas de opressão a que mulheres negras foram submetidas e os seus efeitos nas construções de gênero e de sexualidade, bem como salientando as estratégias de resistência que mulheres de países colonizados desenvolveram frente aos seus sistemas opressores.

No cenário dos estudos de gênero, Heloisa Buarque de Hollanda (2019) associa o desenvolvimento do feminismo decolonial a um período intenso de transformações no campo dos estudos feministas. Conforme a pesquisadora, tais transformações são decorrentes da crise da chamada segunda onda do feminismo, desde a qual, também, se consolidaram estudos importantes no campo da teoria queer, do pós-feminismo e dos 
estudos transgênero. Para Hollanda (2019), as teorias desenvolvidas com início na década de 1980 configuram o período reconhecido como a terceira onda do feminismo, no qual o conceito de gênero emerge com grande ênfase, deslocando o conceito de identidade. A partir do reconhecimento do gênero como uma categoria de análise (SCOTT, 2019) e uma construção performativa (BUTLER, 2019), teóricas e ativistas dos estudos feministas passaram a centrar esforços para notabilizar as formas através das quais a categoria gênero é construída no interior da cultura.

Nesse viés, intelectuais feministas negras têm ressaltado a importância do conceito de interseccionalidade para contemplar a sobreposição de opressões de raça, classe e sexualidade, com base nas quais as mulheres negras são posicionadas. É nesse contexto de reconhecimento das diferentes opressões que as mulheres negras ocupam na sociedade e, dessa forma, da experiência singular de suas trajetórias, que a luta pela representação e pelo direito à participação tornaram-se centrais na agenda feminista.

Sublinhamos o protagonismo das intelectuais feministas afro-americanas como Ângela Davis (2019), Patricia Hill Collins (2019), Bell Hooks (1995) e, no Brasil, Lélia Gonzalez, Sueli Carneiro (2011, 2018) e Djamila Ribeiro (2017), entre outras, na construção de uma epistemologia feminista negra que vem ressignificando as histórias de exploração, deslegitimação, violência, negação e desumanização da população africana e afro-brasileira ao longo do processo afrodiaspórico. Nesse processo, tornou-se fundamental evocar o conhecimento de mulheres negras "anônimas" na historiografia oficial, assim como dar destaque para vozes negras que expressam modos de existir por intermédio de diferentes linguagens, seja pela arte, música, poesia, dança, religiosidade, literatura, ou pela escrita acadêmica, entre outras.

A construção de uma epistemologia feminista negra centra-se, à vista disso, no direito de falar sobre si e tem raízes na histórica luta de diferentes mulheres pelo poder de autodefinição. Como sobreleva a filósofa Djamila Ribeiro (2017, p. 44, grifo da autora), "definir-se é um status importante de fortalecimento e de demarcar a possibilidade de transcendência da norma colonizadora". Também a socióloga norte-americana Patrícia Hill Collins (2019), em Pensamento Feminista Negro, discorre sobre a relevância da autodefinição para as mulheres afro-americanas, principalmente para reverberar a dinâmica de poder imbricada nos processos de definição identitária das mulheres negras. Nesse sentido, "ao enfatizar a autodefinição, as mulheres negras questionam não apenas o que já foi dito sobre as afro-americanas, mas a credibilidade e as intenções daqueles que têm o poder de definir" (COLLINS, 2019, p. 206).

Para Collins (2019), o fato de viverem permanentemente em condições de opressão e sob constante estado de alerta produz uma "dupla consciência" nas mulheres negras: elas se familiarizam e, por vezes, até incorporam a linguagem e o comportamento dos grupos dominantes, como uma estratégia de sobrevivência ou uma forma ilusória de proteção, contudo, também desenvolvem um "ponto de vista autodefinido", geralmente silencioso e íntimo, que é mantido longe dos olhos do opressor. O silêncio, todavia, não pode ser confundido com obediência ou submissão, alerta a socióloga. Dessa maneira, em meio a contextos extremamente adversos, as afroamericanas tiveram que "sustentar autodefinições independentes", rejeitando ou negociando com as imagens de controle produzidas pelos regimes dominantes de poder. Na mesma linha, ela afirma que tem sido central, no pensamento feminista negro, a busca por uma voz individual, que expresse o ponto de vista coletivo e autodefinido das mulheres negras. A busca por essa voz própria advém da necessidade de negociar 
com as contradições que permeiam a relação das mulheres afro-americanas com as imagens internas que constroem de si mesmas e sua objetificação como o Outro.

Portanto, como afirma Collins (2019), dar visibilidade para as histórias individuais de mulheres negras, valorizando suas vivências, suas narrativas e suas memórias têm sido uma importante forma de confrontar as imagens de controle e de resgatar valores e conhecimentos subalternizados e deslegitimados no decorrer da experiência afrodiaspórica ocidental em direção à construção de uma epistemologia centrada na experiência feminina negra.

Ainda, partindo dos estudos de Collins (2019), interessa acentuar as esferas de expressão das vozes das mulheres negras. Entre os "espaços seguros", nos quais elas podiam falar livremente e expressar suas visões de mundo, Collins (2019) evidencia três esferas privilegiadas mediante as quais puderam buscar uma voz: nas relações de mulheres umas com as outras, que se dava nas conversas íntimas entre amigas ou no seio familiar; na tradição do blues, em que as mulheres negras cantavam sua realidade, suas dores e seus amores de uma forma singularmente especial para elas e para a comunidade negra; e, por fim, no trabalho das escritoras negras, que driblando e transcendendo as barreiras de acesso à educação formal, apropriaram-se da escrita a fim de introduzir sua crítica em diferentes contextos, para usos criativos e inventivos.

Seriam as plataformas digitais novas esferas alternativas de expressão de identidades femininas negras? Neste estudo, pretendemos contemplar essa questão, salientando a relevância do espaço virtual para a expressão das vozes das mulheres negras contemporâneas e de suas redes - comunidades de fãs, blogs colaborativos e audiências de influenciadores digitais.

\section{NARRATIVAS AUTOBIOGRÁFICAS DE MULHERES NEGRAS: DAS ESCREVIVÊNCIAS NA LITERATURA ÀS VIDEOGRAFIAS DE SI NA INTERNET}

No campo da literatura brasileira, a escritora Conceição Evaristo (2005a) vem enfatizando que as escritoras negras estão criando outros discursos e representações que colocam sob rasura estereótipos consagrados à mulher afro-brasileira. Consoante a autora, a escrita das mulheres negras é um ato político e transformador, na medida em que projeta outras possibilidades de posição de sujeito, diferentes daquelas projetadas pelo olhar do colonizador. Em entrevista concedida à Djamila Ribeiro, no site Carta Capital, Conceição Evaristo (2017a, n. p.) assegura: "Precisamos mostrar as nossas narrativas, temos que disputar". Por conseguinte, é na arena de disputa por significados que as vozes negras falam, e mais do que isso, fazem-se ouvir. Evaristo utiliza a imagem da escrava Anastácia, que simboliza as históricas tentativas de silenciar a mulher negra, para mostrar que, apesar das máscaras, suas vozes foram e continuam sendo muito potentes.

Aquela imagem de escrava Anastácia [...], eu tenho dito muito que a gente sabe falar pelos orifícios da máscara e, às vezes, a gente fala com tanta potência que a máscara é estilhaçada. E eu acho que o estilhaçamento é o nosso símbolo, porque a nossa fala força a máscara (EVARISTO, 2017a, n. p.). 
PEREIRA, E. S.; ZUBARAN, M. A.

Evaristo (2005b), em Gênero e etnia: uma escre(vivência) de dupla face, relata a sua relação com a oralidade e, mais tarde, com a leitura e a escrita. Ela diz: "do tempo/espaço aprendi desde criança a colher palavras" (EVARISTO, 2005b, p. 219). Com a casa vazia de coisas materiais, porém "habitada por palavras", a escritora menciona que cresceu "possuída pela oralidade", pois tudo era narrado e todos na família contavam. Já a leitura surgiu para ela como "um meio de suportar o mundo" (EVARISTO, 2005b, p. 219) e a escrita, "um modo de ferir o silêncio imposto, ou ainda, executar um gesto de teimosa esperança" (EVARISTO, 2005b, p. 219). Munidas de palavras, Conceição Evaristo e outras literatas negras, como Toni Morrison, no contexto norte-americano, escrevem inventivamente para falar de realidades que são delas e, ao mesmo tempo, de muitas outras mulheres negras. Assim, as escritoras negras criam sistemas simbólicos alternativos, ou autodefinidos, como referiu Collins (2019), que inserem, no corpus literário, novos sentidos para as vidas e as identidades femininas negras. Nesse rumo, Evaristo (2005b, p. 6, grifo da autora) assevera que, na escrita das mulheres negras, "surge a fala de um corpo que não é apenas descrito, mas antes de tudo vivido". É a partir desse formato singular da escrita literária negra que Evaristo (2017b) emprega o conceito de escrevivência. Em Becos da Memória, ela esclarece:

Entre o acontecimento e a narração do fato, há um espaço em profundidade, é ali que explode a invenção. Nesse sentido, venho afirmando: nada que está narrado em Becos da Memória é verdade, nada que está narrado em Becos da Memória é mentira. Ali, busquei escrever a ficção como se estivesse escrevendo a realidade vivida, a verdade. Na base, no fundamento da narrativa de Becos está uma vivência, que foi minha e dos meus. Escrever Becos foi perseguir uma escrevivência (EVARISTO, 2017, p. 13 grifo da autora).

Nesse seguimento, a escrita autobiográfica de mulheres teve e continua tendo um papel elementar na contestação e inversão de estereótipos (HALL, 2014) e no registro da condição feminina negra e suas interpretações sobre o mundo. Claudia Maria Fernandes Corrêa (2013), ao analisar o percurso da narrativa autobiográfica de afroamericanas durante o Movimento pelos Direitos Civis nos Estados Unidos, destaca que a escrita feminina negra foi um importante instrumento para que mulheres negras encontrassem a própria voz e se fizessem ouvir. Corrêa (2013) ressalta que as autobiografias das mulheres negras assumiram, em sua trajetória, duas funções: uma na dimensão individual, que permite a quem escreve interpretar a sua experiência pessoal, e a outra na dimensão coletiva, que, de acordo com a pesquisadora, "possibilita que sua própria vida seja renovada mediante a leitura e a interpretação dos diferentes sujeitos que, unidos, compõem a experiência negra na América do Norte" (CORRÊA, 2013, p. 22). Segundo Corrêa (2013, p. 25), "ao recuperar as raízes, curar feridas, escrever a vida (re)escrevendo a história", as autobiografias "cartografam uma genealogia de perdas, mas, igualmente, redefinem o sentido de 'estar no mundo' para as afro-americanas" (CORRÊA, 2013, p. 25).

Foi na conjuntura de luta pelos Direitos Civis nos Estados Unidos que Maya Angelou escreveu sua primeira autobiografia, em 1969, publicada no Brasil, em 2018, sob o título Eu sei por que o pássaro canta na gaiola. Considerada uma importante referência no gênero, Angelou redigiu, ao longo dos seus 86 anos de idade, sete 
autobiografias. Trazendo reflexões sobre diferentes períodos de sua vida, a escritora traça uma narrativa que mostra como as estruturas sociais operam, demonstrando o seu caráter opressor. No rastro de Angelou, em 1974, Angela Davis, outra grande referência dentro do Feminismo Negro afro-americano, ergueu a voz para contar a sua trajetória. Em Angela Davis: uma autobiografia, ela traz relatos da infância à carreira como professora universitária, culminando nos conflitos políticos que a colocaram na lista das dez pessoas mais procuradas pelo $\mathrm{FBI}$ e a tornaram um ícone do Movimento Negro e Feminista.

No Brasil, quando se fala de escrita autobiográfica de mulher negra, não se pode deixar de referenciar Carolina Maria de Jesus, primeira escritora a narrar a vida na favela, sob o ponto de vista de quem viveu essa realidade. Catadora de papel na antiga favela do Canindé, em São Paulo, a mineira, mãe de três filhos, que vivia em um barracão de madeira às margens do rio Tietê, escrevia seu cotidiano em folhas que encontrava no lixo, como uma forma de desabafar sobre a sua dura realidade. Depois que saiu de Minas Gerais rumo a São Paulo, a escritora relata que morou na rua com os três filhos até ser recolhida por um caminhão e "despejada" na favela do Canindé. Por isso a comparação que faz entre a favela e um quarto de despejo, originando o título de seu primeiro livro, Quarto de Despejo: Diário de uma favelada, publicado em 1960, com o qual ficou mundialmente conhecida.

Grande parte dessas escritas negras, autobiográficas e ficcionais, fazem referência a um "eu" pessoal que ecoa na comunidade, isto é, no coletivo. Na proporção em que narram, essas escritoras constroem autodefinições singulares, ao mesmo tempo em que reproduzem e promovem conhecimentos construídos pelas comunidades negras. Essa é a potência da literatura negra feminina para transcender realidades.

No contexto contemporâneo, com a popularização das tecnologias digitais, as narrativas de si, produzidas por mulheres negras, estão sendo expandidas e ganhando novos formatos. Desse modo, podemos afirmar que, como as escrevivências das escritoras negras citadas anteriormente, as narrativas de si propagadas na internet também produzem efeitos na construção de identidades individuais e coletivas de sujeitos negros.

Pensando a partir dos argumentos de Conceição Evaristo (2005b), sugerimos que as narrativas de si, produzidas no ambiente virtual, podem ser consideradas escrevivências adaptadas para o ambiente digital. Na esteira das escritas de si das pioneiras do Movimento Feminista Negro, cujas as vozes transformaram o pessoal em político, as escrevivências digitais também buscam (re)significar a existência de quem narra e de quem acessa essas narrativas, além de confrontar as estruturas hegemônicas de poder com base em novas dinâmicas. E fazem isso evocando e reconhecendo as memórias e histórias coletivas que constituíram a experiência afro-diaspórica nas Américas.

NARRATIVAS E PEDAGOGIAS NEGRAS DE CONTESTAÇÃO E EMPODERAMENTO NAS MÍDIAS DIGITAIS 
PEREIRA, E. S.; ZUBARAN, M. A.

Nos últimos anos, narrativas de mulheres negras jovens têm proliferado no ambiente virtual, como parte dos processos de autoconstrução identitária das mulheres negras na contemporaneidade. Em geral, essas narrativas escapam aos regimes dominantes de poder, descontruindo estereótipos e estigmas, ressignificando representações e práticas hegemônicas, construindo e disseminando pedagogias negras.

É fundamental realçar que o crescente número de protagonistas negras jovens que se expressam no ambiente virtual, militando por diferentes causas, está associado ao crescente acesso de negros (as) na universidade e aos impactos que o fortalecimento dos Estudos Afro-Brasileiros têm produzido na sociedade brasileira. Essa juventude militante - entre elas algumas influenciadoras digitais negras - faz parte de uma geração que vive os desdobramentos das lutas do Movimento Negro e do Movimento Feminista Negro por políticas públicas de acessos e de garantia de direitos. Uma geração que, de certa maneira, está colhendo os frutos dos embates e dos "passos que vêm de longe".

Neste ínterim, vivemos, hoje, um período no qual a presença de sujeitos negros, de suas demandas e de suas epistemologias está adquirindo maiores proporções em diferentes esferas da cultura, dentre elas, na universidade e nos coletivos de mulheres negras, que não param de se multiplicar no Brasil desde a década de 1980.

Dessa forma, o crescente acesso de jovens negros na universidade, em grande parte resultante das políticas de cotas instituídas no Brasil a datar de 2012, juntamente com a popularização dos smartphones e dos pacotes de internet, que acabaram facilitando a inclusão social por meio das mídias digitais, convergem para instrumentalizar esses jovens para atuarem politicamente na sociedade. Não só por meio da aquisição e da disseminação de informações e conhecimentos, entretanto, sobretudo, através da criação de redes que favorecem a participação e a atuação social.

Em concordância com Sueli Carneiro (2018), as mulheres negras, especialmente as mais jovens, estão tratando a comunicação como um "nexo de empoderamento", tornando a internet um espaço privilegiado para disseminar conhecimentos da cultura e da história afro-brasileira, para dar visibilidade às vivências negras e para "garantir-lhes uma representação positiva, bem como a visibilização do processo de mobilização e de lutas" (CARNEIRO, 2018, p. 209). Para a autora,

\footnotetext{
As mulheres negras vêm atuando no sentido de não apenas mudar a lógica de representação dos meios de comunicação de massa, como também de capacitar suas lideranças para o trato com as novas tecnologias de informação, pois a falta de poder dos grupos historicamente marginalizados para controlar e construir sua própria representação possibilita a crescente veiculação de estereótipos e distorções pelas mídias, eletrônicas ou impressas (CARNEIRO, 2018, p. 209).
}

Nessa perspectiva, notadamente a partir dos anos 2000, a internet passou a interpelar sujeitos negros a assumirem posições de protagonismo na produção de conteúdos digitais. $\mathrm{E}$, ainda que o acesso à rede não seja democrático, pois os meios digitais continuam inacessíveis a muitas pessoas, a internet permite que o poder seja descentralizado e que redes de contestação e disputa por significados sejam criadas, tencionando regimes de verdade e sistemas simbólicos que organizam a cultura e as 
identidades. Sendo assim, levando em conta o estabelecimento da comunicação digital, os sujeitos passam a conectar-se uns aos outros em diferentes redes de interesse, mantidas por meio de sentimentos de proximidade e de pertença.

Os pesquisadores Felice, Pereira e Roza (2017) analisaram a emergência dessas práticas de participação social nas redes digitais, denominadas de net-ativismos, e apontaram que existe nelas uma singular "ecologia de ação". Em consonância com os autores, esses ativismos possuem uma "espacialidade complexa", dado que têm origem nas redes digitais, no entanto, não se limitam a elas, alcançando as ruas e os espaços públicos, como foi o caso das manifestações de julho de 2013, no Brasil, e de outros movimentos semelhantes que aconteceram ao redor do mundo.

A atuação da historiadora negra Giovana Xavier é um bom exemplo de como as mulheres negras vêm utilizando as mídias digitais como "um nexo de empoderamento", objetivando produzir representações positivas de si e para dar visibilidade aos movimentos de luta. A professora, que também é blogueira, sintetiza a observação de Collins (2019, p. 402) de que a academia e os meios de comunicação estão se tornando espaços fundamentais para a atividade intelectual negra. Xavier é professora na Faculdade de Educação da Universidade Federal do Rio de Janeiro, onde desenvolve atividades voltadas a reforçar a produção intelectual e o trabalho de mulheres negras em diferentes áreas. Concomitante ao trabalho na academia, ela utiliza a internet para divulgar sua produção intelectual e seu ativismo em prol da visibilidade e positivação das identidades femininas negras. Na página do Grupo de Estudos e Pesquisas Intelectuais Negras do qual faz parte como fundadora e pesquisadora, Xavier (2014, n. p.) declara que "a produção de saberes científicos é uma forma de ativismo" e, por isso, "autodefine-se como afroempreendedora acadêmica, uma vez que tem como foco contribuir para formação acadêmica de intelectuais negros e negras" (XAVIER, 2014, n. p.).

Em sua produção intelectual, Giovana Xavier (2017) vem consolidando que as mulheres negras foram pioneiras em projetos e intervenções em prol da igualdade e da liberdade. Sobre isso, ela expõe: "se a palavra feminismo é branca e ocidental, a prática feminista é negra e diaspórica" (XAVIER, 2017, n. p.). Em sua opinião, para que uma única história fosse contada e um único feminismo fosse legitimado, muitas outras histórias foram apagadas, muitas vozes foram reprimidas e muitas humanidades foram negadas. Xavier (2017) salienta que cabe às mulheres negras o compromisso de dar evidência às múltiplas histórias e vivências negras, não só de dores e denúncias, e sim, mormente, de vitória, beleza e criatividade. Interpretar essas experiências e narrar em primeira pessoa as múltiplas formas de viver a identidade feminina negra, a partir das posições sociais que ocupam na sociedade, é uma forma de restituir humanidades negadas. Nas palavras da historiadora,

Narrar na primeira pessoa as nossas histórias de beleza, força e sucesso é parte dessa restituição, pois produzir nossos próprios saberes a partir de quem somos e do que sonhamos representa revidar com a poderosa arma da beleza, o anonimato, a pobreza, o preterimento e os alarmantes indicadores sociais como a história única pela qual somos vistas e narradas. Significa a aposta em um 
PEREIRA, E. S.; ZUBARAN, M. A.

projeto de humanidade negra comprometido em conferir visibilidade a trajetórias que nos fazem enxergar a diversidade que nos constitui. As potências que carregamos, multiplicamos e que estão ausentes dos grandes meios de comunicação (XAVIER, 2017, n. p.).

Para as mulheres negras, definir-se através de suas próprias narrativas é um ato político e de sobrevivência, cria esperança e possibilidades de vida frente ao genocídio, à violência, ao feminicídio, ao encarceramento, ao epistemicídio e à toda forma de violência e massacre da população negra.

No campo dos Estudos Culturais e dos Estudos Feministas Negros, as identidades raciais são construídas discursivamente no interior da cultura, através da marcação arbitrária e hierárquica da diferença. Isso equivale a dizer que raça e etnia não são categorias fixas, pautadas em dados biológicos e indiscutíveis, ou que possuam uma origem definida e imutável. As identidades raciais são cambiantes e dependem de uma relação constante com a diferença. Tal como certifica Tomaz Tadeu da Silva (2014, p. 101), "precisamente por dependerem de um processo histórico e discursivo de construção da diferença, raça e etnia estão sujeitas a um constante processo de mudança e transformação".

Partindo desse entendimento e da observação de que os processos de racialização, no Brasil, estão passando por importantes transformações nos últimos anos, o interesse deste estudo é observar que sentidos estão sendo acionados por mulheres negras jovens, maiormente as que utilizam o ciberespaço como um ambiente de sociabilidade de relevância em suas vidas, para conformarem uma identidade racial negra.

Como já mencionado anteriormente, em meio ao oceano de produtores de conteúdo que alimentam a internet de forma veloz e incessante, cresce um nicho específico de influenciadoras digitais negras que disseminam narrativas de enfrentamento ao racismo e de empoderamento político e estético para a sua audiência negra. Entre elas, a youtuber Nátaly Neri se sobressai pela crescente popularidade que vem alcançando no ambiente digital. Recentemente formada em Ciências Sociais na Universidade Federal de São Paulo, a jovem de 26 anos iniciou o seu canal Afros e Afins no ano de 2015, um pouco depois de ingressar no Ensino Superior.

Filha de mãe negra e pai branco, Nátaly Neri é uma mulher negra de pele clara, cujo processo identitário foi atravessado pelas políticas de embranquecimento que pautam os discursos hegemônicos de racialização no cenário brasileiro. Grande parte das narrativas veiculadas no canal Afros e Afins abordam os processos de transformação pessoal da youtuber, nos âmbitos emocional, intelectual, religioso e político, em direção a um "tornar-se negra". Quem acessa o conteúdo que Nátaly Neri produz na internet, acompanha uma trajetória de desafios e deslocamentos subjetivos e identitários atravessados pelas lutas das mulheres negras de seu tempo, em especial, pelas discursividades que emergem das lutas dos Movimentos Negros e das epistemologias de intelectuais feministas negras.

Em um de seus vídeos, denominado Colorismo, ser negro e os 3 mitos da mulher negra, publicado em fevereiro de 2016, Nátaly Neri discute o processo de autodefinição racial de mulheres negras de pele clara em uma sociedade colorista. Descreve que passou a ser constantemente interpelada a falar sobre a linha tênue e 
cambiante que delineia as categorias de raça e a autodefinição dos sujeitos negros. Nesse vídeo, a youtuber relata que recebe muitas mensagens perguntando sobre os limites da negritude, demostrando que há um grande interesse de sua audiência em compreender os seus próprios processos identitários a partir de novas bases e novos pontos de vista. Isto é, a partir do conjunto de conhecimentos colocados em circulação na sociedade brasileira por pesquisadores, intelectuais e militantes ligados ao movimento negro, ou mesmo por sujeitos que, de algum modo, foram afetados por esses conhecimentos e que passaram a reivindicar e reiterar uma identidade racial negra.

Essas pessoas querem que eu responda, o que é ser negro? O que é não ser negro? Qual é o limite entre uma negra de pele clara e uma branca? Eu nunca vou poder dizer isso pra [sic] você (NERI, 2016, n. p.). ${ }^{1}$

Diferente de outros países com um passado colonial, como os Estados Unidos, por exemplo, onde as categorias raciais são binárias e definidas pela origem, no Brasil, foram sendo desenvolvidas categorias que mesclam cor e raça, de forma que passam a ser compreendidas como sinônimos (pardo, mameluco, caboclo, moreno, mulato). Tais categorias servem como um guarda-chuva para classificar os sujeitos que não são considerados, ou não se consideram, brancos. Conforme Sueli Carneiro (2011), a categoria pardo, essa "zona cinzenta", serve como abrigo para todos aqueles (as) que não se desejam negros (as), um lugar onde podem "se esconder e se esquecer de uma origem renegada" (CARNEIRO, 2011, p. 60).

Em outro vídeo, intitulado Empoderamento estético e consciência racial, publicado em 18 de novembro de 2017, Nátaly Neri relata que, por um longo período de sua vida, experienciou a indefinição racial. Isso, consoante Carneiro (2011), é aceito, pela sociedade brasileira, como natural, posto que a identidade branca foi construída discursivamente como a norma e o ideal de beleza, de educação, de civilidade, de valores e de superioridade. Escapar da negritude através de diferentes mecanismos de embranquecimento foi, e ainda é, uma forma de fugir do racismo, como mostra o excerto a seguir:

[...] como eu sabia que eu era uma pessoa negra, e eu já entedia desde muito cedo, a sociedade me fez entender, desde muito cedo, que ser negro era um coisa ruim, eu tentei de todas as formas me embranquecer. Eu me imaginava, eu me via, como uma pessoa exatamente no meio de um muro. De um lado, negros, de outro, brancos. E se eu tô [sic] no meio eu poderia cair pro [sic] lado branco. Por que não? Por que não viver uma vida de privilégios? (NERI, 2017, n. p.). ${ }^{2}$

Como é possível verificarmos nos trechos apresentados acima, a identidade é sempre uma questão de "tornar-se", ou seja, não existe uma essência de "quem nós realmente somos" que remeta a uma origem e que possa ser descoberta e explorada, ela é resultado de um investimento constante naquilo que queremos "nos tornar". Por essa 
lógica, para a população negra brasileira, foi interposto um grande problema em termos identitários no decorrer da história. Carneiro (2011, p. 58) explana: "aprendemos a não saber o que somos e, sobretudo, o que devemos querer ser". Sobre essa dimensão do devir negro, Hall (2014) argumenta que, embora as identidades pareçam invocar uma origem comum que defina "quem se é", o que está no cerne das construções identitárias é a possibilidade de recorrer aos recursos da história, da linguagem e da cultura para reconstruir e ressignificar o presente e o futuro, ou melhor, para dar novos sentidos ao "quem se quer ser".

Dado o contexto histórico desde o qual os sistemas de classificação racial foram construídos discursivamente no Brasil, é basilar para a luta antirracista e para a construção de um devir negro positivo disseminar conhecimentos e sistemas culturais não hegemônicos produzidos por vozes historicamente silenciadas. Conhecimentos que denunciem a forma violenta, em termos físicos e simbólicos, como tentam apagar a negritude da história e que também promovem saberes e formas alternativas de interpretar a história e de significar o mundo.

Observamos, nas narrativas de Nátaly Neri, que, além do compartilhamento de suas experiências pessoais na conformação de uma identidade negra, há um forte interesse em disseminar conhecimentos contra-hegemônicos para outras mulheres negras. Sua preocupação em traduzir conceitos pertinentes à compreensão da trajetória da população negra nos processos afrodiaspóricos é notada no excerto apresentado a seguir. Nele, percebemos que a jovem busca explicar para a sua audiência como as categorias raciais foram sendo construídas pelos grupos dominantes a começar no final do século XIX, por meio de um projeto de embranquecimento da população brasileira. Para isso, a youtuber aciona e traduz conceitos e teorias, tais como colorismo, pigmentocracia e embranquecimento, para uma linguagem simples e direcionada ao seu público, que é majoritariamente composto por jovens.

Pra [sic] começar, gente, colorismo é um termo, tipo, é um conceito mega simples, que também pode ser conhecido como pigmentocracia, que é basicamente você dizer que, quanto mais escuro você for, mais racismo você vai sofrer. E quanto mais claro você for, mesmo você sendo negro, mais privilégios, privilégios entre aspas, você vai ter. Quem criou esse termo foi Alice Walker, em 1982. Ela falou: colorismo é isso, pá. Só que a gente já tinha, no Brasil, trazendo aqui pro [sic] Brasil... por volta de 1910, por aí, começou a vim uma loucura de uma doutrina muito louca que se dizia científica, que era a teoria do embranquecimento. Dizia assim: olha, o Brasil é uma bagunça, o Brasil tem índio, preto, branco, o Brasil é uma mistura, o Brasil não tem identidade. Ou seja, a gente precisa de uma ordem aqui, e essa ordem só pode ser colocada pelo homem branco civilizado. Então, lá pra [sic] 1910 veio uma galera que trouxe essa teoria pra [sic] cá e eles tinham um plano de embranquecer o Brasil em um século. Ou seja, trazer vários imigrantes europeus pra [sic], tipo, virar todo mundo branco porque só assim o Brasil iria evoluir. Em 1920, por aí, veio uma galera europeia que foi mais pro [sic] sul do Brasil, como a gente sabe e tal. A gente tem uma nação que foi forçada politicamente a se embranquecer (NERI, 2016, n. p.). ${ }^{3}$ 
Em suas falas, Nátaly Neri salienta que a autodefinição racial é um processo individual, em que o próprio sujeito precisa reconhecer-se. E, caso se reconheça negro (a), deve reivindicar essa identidade e investir nela. Reconhecer-se negro, para a youtuber, não está relacionado somente ao fenótipo e ao reconhecimento de situações de racismo, e sim à identificação com sistemas culturais e valores de uma comunidade de origem comum, imaginada e reconstruídas nos processos diaspóricos.

A youtuber busca descolar a identidade racial da aparência física, criticando o termo pardo enquanto definição racial. Ela ressalta que a indefinição que o termo pardo carrega e que Carneiro (2011) chamou de "zona cinzenta" é resultado da tentativa sistêmica de embranquecer a população brasileira, diluindo a negritude e os seus sistemas culturais. Com essa crítica, instiga seus seguidores a, assim como ela, também negarem essa categoria e a autodeclararem-se negros (as) de pele clara e negros (as) de pele escura.

\section{CONSIDERAÇÕES FINAIS}

No decorrer deste estudo, pretendemos evidenciar o modo como a visibilidade e a valorização de sistemas culturais afro-brasileiros e de estéticas negras vêm contribuindo de modo crescente para uma mudança em relação à forma como sujeitos negros, precipuamente mulheres, autodefinem-se na atualidade. A partir das narrativas e representações de Nátaly Neri, que tratam do seu processo individual em busca de "tornar-se uma mulher negra" orgulhosa de sua identidade racial, buscamos enfatizar a maneira como representações alternativas da estética negra contribuem para produzir importantes deslocamentos identitários na comunidade negra jovem em direção a um "tornar-se negro(a)".

Conforme destacado ao longo do texto, muitas intelectuais negras têm disseminado o poder da autodefinição racial e a importância de as mulheres negras tomarem a palavra para narrarem e representarem a si mesmas baseadas na experiência singular de cada uma, complexificando e pluralizando significados e sentidos que constituem as múltiplas experiências de ser mulher negra em determinado contexto histórico-cultural. Mesmo reconhecendo que esses passos vêm de longe, as dinâmicas culturais da pós-modernidade, aliadas às tecnologias digitais, estão impulsionando o protagonismo de jovens mulheres negras em direção à construção de novas formas de ativismo e positivação das identidades raciais negras.

Nesse sentido, é possível afirmar que as pedagogias culturais produzidas e disseminadas por youtubers negras, como Nátaly Neri, estão tencionando estereótipos, fazendo circular representações de formas alternativas de ser e de viver as identidades negras, constituindo, em consequência, o que se pode chamar de pedagogias negras digitais de contestação e de empoderamento. Essas narrativas produzidas por influenciadoras digitais afro-brasileiras têm colocado em destaque mulheres negras com formação universitária, altamente politizadas e conectadas, que transitam por diferentes espaços sociais e que produzem conhecimentos que põem em xeque os pilares da opressão que por séculos Ihes invisibilizou e silenciou. 
PEREIRA, E. S.; ZUBARAN, M. A.

Artigo recebido em: 01/04/2021

Aprovado para publicação em: 14/10/2021

THE CONSTITUTION OF BLACK PEDAGOGIES ON THE INTERNET: A STUDY OF NARRATIVES PRODUCED AND DISSEMINATED BY BLACK YOUTUBERS

ABSTRACT: This study addresses the narratives and pedagogies produced and disseminated by black Youtubers in the virtual environment. The main objective of the article is to analyze how cultural pedagogies are constructed and narrated in digital spaces and to measure their impact on the construction of black female identities. The research is located in the field of Cultural Studies in Education and the methodology used is cultural analysis, inspired by virtual ethnography. Among the main results of the research, it is highlighted that the self-narratives produced by black digital influencers are configured as part of the new contemporary activisms, as new forms of resistance and self-definition of alternative black female identities that trigger cultural pedagogies of contestation and empowerment of young black women.

KEYWORDS: Black Youtubers. Digital Narratives. Black Pedagogies.

LA CONSTITUCIÓN DE LAS PEDAGOGÍAS NEGRAS EN INTERNET: UN STÚDIO DE LAS NARRATIVAS PRODUCIDAS Y DIVULGADAS POR YOUTUBERS NEGRAS

RESUMEN: Este estudio aborda las narrativas y las pedagogías culturales producidas y difundidas por las youtubers negras en el entorno virtual. El objetivo principal del artículo es analizar cómo se construyen y narran las pedagogías culturales en los espacios digitales y medir su impacto en la construcción de identidades femeninas negras. La investigación se ubica en el campo de los Estudios Culturales en Educación y la metodología utilizada es el análisis cultural, inspirado en la etnografía virtual. Entre los principales resultados de la investigación, se destaca que las narrativas de sí producidas por influencers digitales negras se configuran como parte de los nuevos activismos contemporáneos, como nuevas formas de resistencia y autodefinición de identidades alternativas femeninas negras que desencadenan pedagogías culturales de contestación y empoderamiento de las jóvenes negras.

PALABRAS CLAVE: Youtubers Negras. Narrativas Digitales. Pedagogías Negras.

\section{NOTAS}

1 - No vídeo Colorismo, ser negro e os 3 mitos da mulher negra, do canal Afros e Afins, de Nátaly Neri, o trecho destacado encontra-se entre os tempos de 8:54 min a 9:45 min. O vídeo está disponível em: www.youtube.com/watch?v=DGGaLz_NYDo\&ab_channel=NátalyNeri.

2 - No vídeo Empoderamento estético e consciência racial, do canal Afros e Afins, de Nátaly Neri, o trecho destacado encontra-se entre os tempos de 3:30 min a 3:58 min. O vídeo está disponível em: www.youtube.com/watch?v=iy1 niabC1eQ\&ab_channel=NátalyNeri.

Inter-Ação, Goiânia, v.46, n.3, p. 1508-1523, set./dez. 2021. Disponível em: <http://dx.doi.org/10.5216/ia.v46i3.68472>. 
3 - No vídeo Colorismo, ser negro e os 3 mitos da mulher negra, do canal Afros e Afins, de Nátaly Neri, o trecho citado encontra-se entre os tempos de 0:22 min a 1:42 min. O vídeo está disponível em: www.youtube.com/watch?v=DGGaLz_NYDo\&ab_channel=NátalyNeri.

\section{REFERÊNCIAS BIBLIOGRÁFICAS}

ANGELOU, M. Eu sei por que o pássaro canta na gaiola. São Paulo: Astral Cultura, 2018.

BUTLER, J. Atos performáticos e a formação dos gêneros: um ensaio sobre fenomenologia e teoria feminista. In: HOLLANDA, Heloisa Buarque (org.). Pensamento feminista: conceitos fundamentais. Rio de Janeiro: Bazar do Tempo, 2019. p. 213-230.

CAMOZZATO, V. C. Da pedagogia às pedagogias - formas, ênfases e transformações. 2012. Tese (Doutorado em Educação) - Faculdade de Educação, Universidade Federal do Rio Grande do Sul, Porto Alegre, 2012.

CARNEIRO, S. Racismo, sexismo e desigualdade no Brasil. São Paulo: Selo Negro, 2011.

CARNEIRO, S. Escritos de uma vida. Belo Horizonte: Letramento, 2018.

COLLINS, P. H. Pensamento feminista negro: conhecimento, consciência e a política do empoderamento. São Paulo: Boitempo, 2019.

CORRÊA, C. M. F. Reflexos em um espelho de ébano: a autobiografia afroamericana feminina durante o movimento pelos direitos civis. Revista Educação e Linguagens, Campo Mourão, v. 2, n. 3, p. 19-28, jul./dez. 2013.

DAVIS, A. Uma autobiografia. São Paulo: Boitempo, 2019.

EVARISTO, C. Da representação à auto-apresentação da Mulher Negra na Literatura Brasileira. Revista Palmares, Brasília, ano 1, n.1, p. 52-57, agosto de 2005a.

EVARISTO, C. Gênero e etnia: uma escre(vivência) de dupla face. In:SCHNEIDER, N. M. de B. M. L. (org.). Mulheres no mundo: etnia, marginalidade e diáspora. João Pessoa: Ideia, 2005b. p. 218-229.

EVARISTO, C. "Nossa fala estilhaça a máscara do silêncio". Entrevista concedida à Djamila Ribeiro, em 10 de maio de 2017. Revista Carta Capital [online]. Disponível em: https://www.cartacapital.com.br/sociedade/conceicao-evaristo-201 cnossa-falaestilhaca-a-mascara-do-silencio201d. Acesso em: 20 jun. 2018.

EVARISTO, C. Becos da Memória. Rio de Janeiro: Pallas, 2017b. 
PEREIRA, E. S.; ZUBARAN, M. A.

FELICE, M. Di; PEREIRA, E.; ROZA, E. (org.). Net-ativismo: Redes digitais e novas práticas de participação. Campinas: Papirus, 2017.

GONZALEZ, L. Primavera para as rosas negras: Lélia Gonzales em primeira pessoa. São Paulo: Diáspora Africana, 2018.

HALL, S. Que "negro" é esse na cultura negra. In:Da Diáspora - Identidade e Mediações Culturais. Belo Horizonte: UFMG, 2014. p. 335-349.

HOOKS, B. Intelectuais Negras. Revista Estudos Feministas, Florianópolis, v. 3, n. 2, p. 464-478, 1995.

JESUS, C. M. de. Quarto de Despejo: Diário de uma favelada. Rio de Janeiro: Franscisco Alves, 1960.

LUGONES, M. Rumo a um feminismo decolonial. In: HOLLANDA, Heloisa Buarque (org.). Pensamento feminista: conceitos fundamentais. Rio de Janeiro: Bazar do Tempo, 2019. p. 357-377.

NERI, N. Empoderamento estético e consciência racial. São Paulo, 18 nov. 2017. Canal Afros e Afins. Disponível em:

www.youtube.com/watch?v=iy1 niabC1eQ\&ab_channel=NátalyNeri. Acesso em: 28 fev. 2021.

NERI, N. Colorismo, ser negro e os 3 mitos da mulher negra. São Paulo, 01 fev. 2016. Canal Afros e Afins. Disponível em: www.youtube.com/watch?v=DGGaLz_NYDo\&ab_channel=NátalyNeri. Acesso em: 28 fev. 2021.

RIBEIRO, D. O que é lugar de fala? Belo Horizonte: Ed. Letramento, Justificando, 2017.

SCOOT, J. Gênero: uma categoria útil para análise histórica. In:HOLLANDA, Heloisa Buarque (org.). Pensamento feminista: conceitos fundamentais. Rio de Janeiro: Bazar do Tempo, 2019. p. 49-80.

SILVA, T. T. Documentos de identidade: Uma introdução as teorias do currículo. 3. ed.; $5^{\text {a }}$ reimp. Belo Horizonte: Autêntica Editora, 2014.

WERNWCK, J. Nossos passos vêm de longe! Movimentos de mulheres negras e estratégias políticas contra o sexismo e o racismo. Revista da ABPN, Goiânia, v. 1, n. 1, p. 7-17, mar/jun. de 2010.

WORTMANN, M. L. C. Pedagogia, cultura e mídia: algumas tendências, estudos e perspectivas. In: BUJES, Maria Isabel E.; BONIN, lara Tatiana (orgs.). Pedagogias sem fronteiras. Canoas: ed. ULBRA, 2010. p. 105-122.

Inter-Ação, Goiânia, v.46, n.3, p. 1508-1523, set./dez. 2021. Disponível em: <http://dx.doi.org/10.5216/ia.v46i3.68472>. 
XAVIER, G. Feminismo: direitos autorais de uma prática linda e preta. Blog Folha de S. Paulo, São Paulo, 19 jul. 2017. Disponível em:

https://agoraequesaoelas.blogfolha.uol.com.br/2017/07/19/feminismo-uma-praticalinda-e-preta/. Acesso em: 28 fev. 2021.

XAVIER, G. Quem somos. Grupo de Estudos Intelectuais Negras. Rio de Janeiro: UFRJ. Disponível em https://www.intelectuaisnegras.com/quem-somos. Acesso em: $28 \mathrm{fev}$. 2021.

Evelyn Santos Pereira: Doutorado em Educação, com ênfase nos Estudos Culturais, na Universidade Luterana do Brasil. Professora da rede municipal de Canoas.

Orcid: https://orcid.org/0000-0002-1103-7613

E-mail: evelynsantospereir@yahoo.com.br

Maria Angélica Zubaran: Doutorado em História na State University of New York; Pós-doutorado no Birkbeck College da London University. Professora adjunta do Curso de História e do Programa de Pós-Graduação em Educação da Universidade Luterana do Brasil (PPGEdu), Pesquisadora do NEABI/Ullbra.

Orcid: https://orcid. org/0000-0002-7506-7387

E-mail: angelicazubaran@yahoo.com.br

Este periódico utiliza a licença Creative Commons Attribution 3.0, para periódicos de acesso aberto (Open Archives Initiative - OAI). 